\title{
Economic Comparison of Electric Vehicles Performing Unidirectional and Bidirectional Frequency Control in Denmark with Practical Validation
}

Thingvad, Andreas; Martinenas, Sergejus; Andersen, Peter Bach; Marinelli, Mattia; Christensen, Bjørn E.; Olesen, Ole Jan

Published in:

2016 Proceedings of the 51st International Universities Power Engineering Conference

Link to article, DOI:

10.1109/UPEC.2016.8113988

Publication date:

2016

Document Version

Peer reviewed version

Link back to DTU Orbit

Citation (APA):

Thingvad, A., Martinenas, S., Andersen, P. B., Marinelli, M., Christensen, B. E., \& Olesen, O. J. (2016).

Economic Comparison of Electric Vehicles Performing Unidirectional and Bidirectional Frequency Control in

Denmark with Practical Validation. In 2016 Proceedings of the 51st International Universities Power Engineering Conference IEEE. https://doi.org/10.1109/UPEC.2016.8113988

\section{General rights}

Copyright and moral rights for the publications made accessible in the public portal are retained by the authors and/or other copyright owners and it is a condition of accessing publications that users recognise and abide by the legal requirements associated with these rights.

- Users may download and print one copy of any publication from the public portal for the purpose of private study or research.

- You may not further distribute the material or use it for any profit-making activity or commercial gain

- You may freely distribute the URL identifying the publication in the public portal 


\section{Economic Comparison of Electric Vehicles Performing Unidirectional and Bidirectional Frequency Control in Denmark with Practical Validation}

\author{
Andreas Thingvad, Sergejus Martinenas, \\ Peter Bach Andersen, Mattia Marinelli, Ole Jan Olesen \\ Center for Electric Power and Energy, Department of Electrical Engineering \\ DTU - Technical University of Denmark \\ Contact Person: Andreas Thingvad, athing@student.dtu.dk
}

\author{
Bjoern E. Christensen \\ CSO, NUVVE Corporation \\ El Cajon, California - USA
}

\begin{abstract}
The paper aims at investigating different methods, based on unidirectional charge and Vehicle-to-Grid (V2G), in order to evaluate and compare the potential economic revenue for an EV owner in providing frequency control in Denmark. User constraints are considered while evaluating the daily duration the EV is plugged into the network ready to support the system frequency. Performing unidirectional frequency control with Electric Vehicles (EVs) requires little hardware implementation in the household but has the limit that the service only can be performed until the battery is fully charged. Bidirectional V2G frequency control requires an external charger but also enables the EV to perform services at higher powers, during the entire period the EV is parked. The yearly revenue is in both cases calculated using some assumptions that are then verified in 2 experiments. Both EVs are discharged with the same amount of energy, such that their initial State of Charge (SOC) is set to the same level.
\end{abstract}

\section{INTRODUCTION}

As the share of renewable energy sources in the grid increases, the power balance becomes harder to maintain because the production is more fluctuating and depending on the weather conditions. At the same time, a fast increasing number of EVs are considered a large additional load by the grid operators, as each EV doubles the households power consumption [1], [2].

On the other hand, EVs are distributed storage units of 16-90 $\mathrm{kWh}$ that are only driven $4 \%$ of the time and can be used for a secondary purpose $96 \%$ of the time [3]. In large quantities they contain a large potential for performing grid services.

As a way of resolving the need for balancing reserves a possible contribution by intelligent integration of EVs in the grid is being discussed [4], [5]. Balancing reserve could be provided either by simply modulating the charge (i.e., unidirectional charge) or by allowing a reverse power flow from the EV (i.e., bidirectional charge). While modulation of unidirectional charge is relatively simple and requires limited hardware modification, bidirectional or V2G charge may be less straightforward to implement, especially when utilising domestic charging power levels. Future EVs could also be build with an internal bidirectional charger and thereby perform V2G with equally little hardware implementation in the household [6].

V2G enables the EVs to perform services at higher powers during the entire period the EV is parked. It is a trade off between the implementation complexity and the possible revenue. The starting hypothesis of this work is that it is possible to earn more with $\mathrm{V} 2 \mathrm{G}$ than with a unidirectional EV [7]. Assessing by which factor it is more lucrative, is important for the EV owner and for the original equipment manufacturer (OEM). The aim of this work is to evaluate the performance of both approaches (unidirectional charge and V2G) when performing Frequency Normal-operation Reserve (FNR) in Eastern Denmark (DK2) [8]. The evaluation is done by comparing the assessed yearly revenue and then experimentally validating that the EVs are able to perform the service with the specifications that are used for the calculations.

\section{METHODOLOGY}

Using Denmark as a test case, it is assessed how much an EV owner could expect to earn from performing unidirectional frequency support or V2G. The following assumptions were made for the calculations:

- The average travel distance per day in Denmark, including weekends and holidays, is $39.5 \mathrm{~km}$ [9]. That corresponds to a daily electrical energy consumption of $5.2 \mathrm{kWh}$, driving with a Citroën Berlingo Electric [10].

- The EV is assumed to be connected to the home charger in the period 16:00-07:00 every day.

- A frequency measurement is in both cases used to generate a control signal that the EV should follow in order to receive the payment. FNR are bought in hour blocks and the EV owner will only receive compensation for the number of full hours the service can be performed.

- The EVs are charged using a domestic power level of 16 A $230 \mathrm{~V}$. 


\section{A. Frequency Normal-operation Reserve}

FNR contributes to ensuring that production and consumption balance is maintained. The regulation is automatic and responds to frequency deviation, measured locally, without a dead band. The reserve is symmetric which means that the service supplier must be available with the same amount of upwards and downwards control power. According to the grid code the reserve must be applied linearly with $100 \%$ deployment for deviations of $\pm 100 \mathrm{mHz}$. Regardless of the size of the deviation the reserve must be implemented within $150 \mathrm{~s}$.

FNR is compensated per MW per hour the service is made available. The hourly mean for the whole year is seen in Fig. 1 and it is clear that the price follows a trend depending on the time of the day with the highest prices at night. The compensation is very fluctuating as it is determined by the principles of demand and supply. The low price in 2015 is by Energinet.dk explained by a large amount of rain in Sweden resulting in a larger production of hydro power as DK2 and Swedish markets are tightly coupled. The mean of the last 3 years is used for calculating the revenue as the business model would have to be viable over several years.

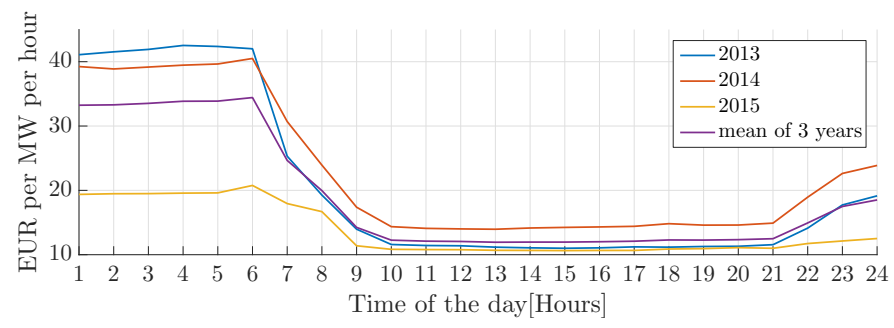

Fig. 1. Mean FNR prices for 3 years

\section{B. Droop Curves for Unidirectional and V2G charging}

Most mass produced EVs can charge with 16 A using the internal AC/DC converter. This is referred to as mode 3 according to the IEC 62196-1 standard. The lowest charging value allowed by the standard is $6 \mathrm{~A}$. When performing unidirectional FNR with a single EV, the charging set point will be set to $11 \mathrm{~A}$ such that the current can be changed with \pm 5 A for a range of 6-16A [11]. The CHAdeMO protocol describes fast DC charging up to $62.5 \mathrm{~kW}$ and contains information about the SOC of the EV. It allows the external charger to connect directly to the EVs battery and it allows for bidirectional power transfer. It is referred to as type 4 in the IEC 62196-3 standard. Nissan LEAF, which is enabled to perform V2G via the CHAdeMO plug, is able to modulate its charging power from $-16 \mathrm{~A}$ to $+16 \mathrm{~A}$. The resulting droop curve can be seen in Fig. 2.

It is assumed that the EV is fully charged minus $5.2 \mathrm{kWh}$ and connected to the grid in the hours 16:00-07:00 every day for a year.

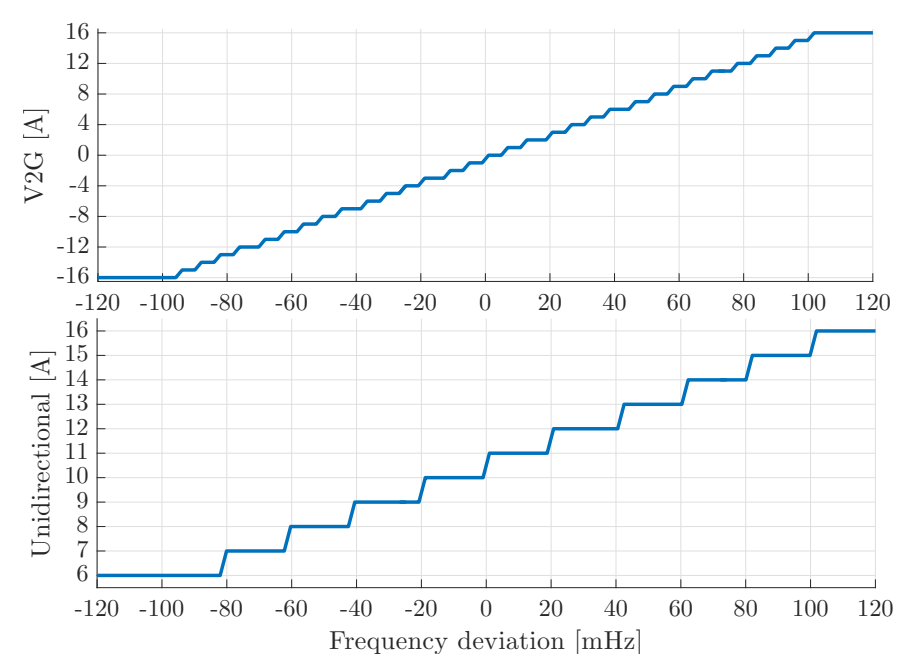

Fig. 2. Droop of unidirectional and V2G FNR provision.

TABLE I

PREREQUISITE FOR CALCULATIONS.

\begin{tabular}{|l|l|l|c|c|}
\hline Method & $\begin{array}{l}\text { Charging } \\
\text { period }\end{array}$ & $\begin{array}{l}\text { Current } \\
\text { range }\end{array}$ & $\begin{array}{c}\text { Power } \\
\text { range }\end{array}$ & $\begin{array}{c}\text { Available } \\
\text { capacity }\end{array}$ \\
\hline Unidirectional & $16-07: 00$ & $6-16 \mathrm{~A}$ & $\pm 1.15 \mathrm{~kW}$ & $5.2 \mathrm{kWh}$ \\
\hline V2G & $16-07: 00$ & $\pm 16 \mathrm{~A}$ & $\pm 3.7 \mathrm{~kW}$ & $5.2 \mathrm{kWh}$ \\
\hline
\end{tabular}

\section{SIMULATION, ANALYSIS AND RESULTS}

\section{A. Grid frequency pattern}

An analysis of the grid frequency behaviour has been made on data contain the grid frequency in RG Nordic for all of 2013 measured every 10 s. Fig. 3 shows a histogram of the data plotted together with the Gaussian distribution with the mean $50.00 \mathrm{~Hz}$ and the variance $\sigma^{2}=0.0018 \mathrm{~Hz}$.

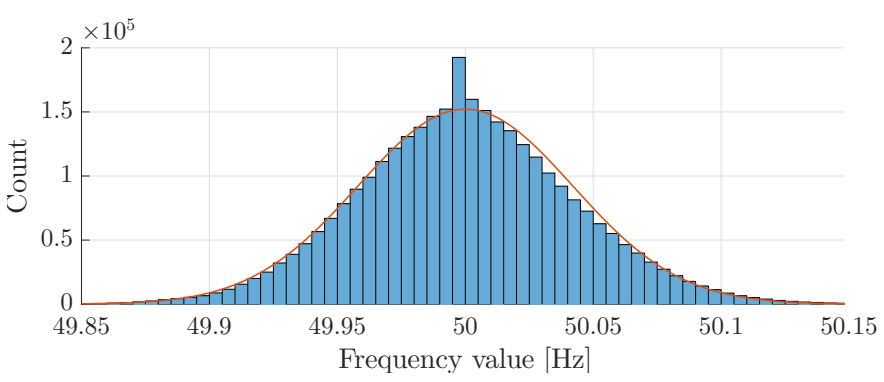

Fig. 3. Histogram with bin width $5 \mathrm{mHz}$ of the grid frequency in RG Nordic for all of 2013 measured every $10 s$.

As $50 \mathrm{~Hz}$ is the mean, the EV should theoretically be able to perform V2G indefinitely as it should charge as much as it discharges. There are however limitations that are described in the V2G section.

The histogram does not contain information about the temporal trends of the grid frequency. There are specific time dependent trends for the grid frequency fluctuations, which are highlighted in Fig. 4. In the figure the frequency deviation from $50 \mathrm{~Hz}$ is shown as a colour for every time of the day 
and every day of the year. There is a clear correlation between the grid frequency fluctuations and the sunset time. There are periods; for instance, after midnight, it is likely that the EV owner would be asked to charge at a lower current to compensate for an under frequency.

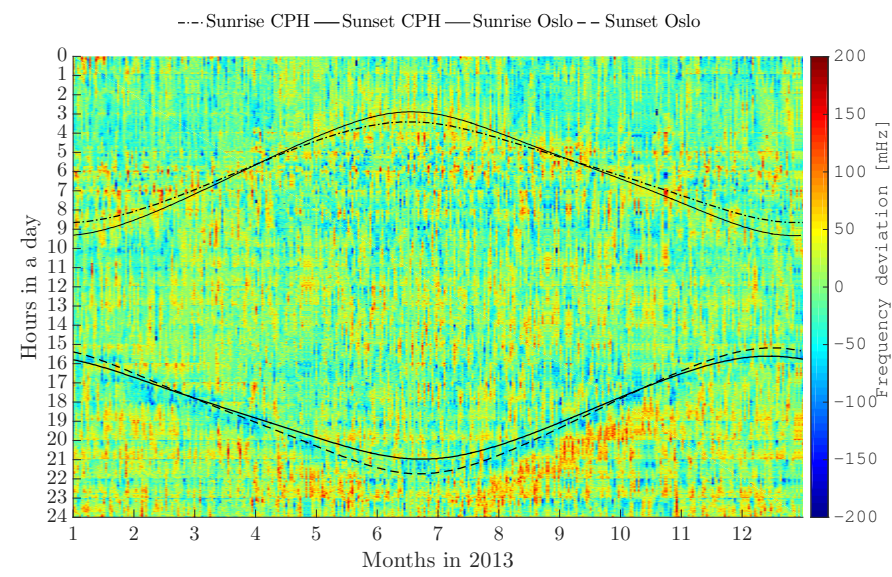

Fig. 4. Frequency deviation during all of 2013 with times of sunset and sunrise in Oslo and Copenhagen.

To demonstrate experimentally the effect of the frequency on the charging, the recorded frequency data seen in Fig. 5 is used. This data set is measured with a sample rate of $1 \mathrm{~s}$. Comparing with Fig. 4 it is clear that our experimental data set is representative of typical frequency variations, with an under frequency around 18:00 and again around 00:00. The mean for the entire period is $50 \mathrm{~Hz}$. The periods with an under frequency is marked in blue and periods with over frequency is marked in red.

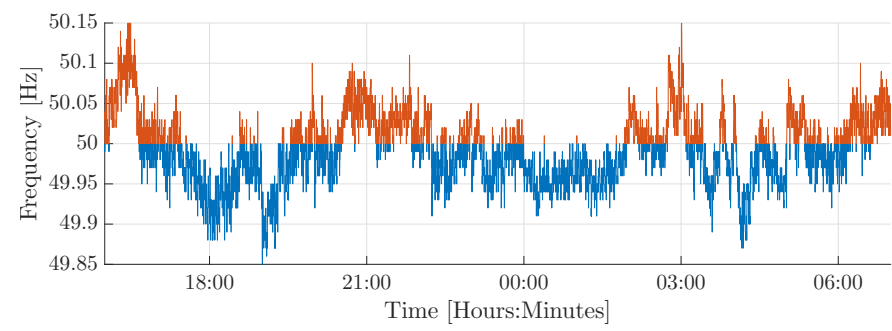

Fig. 5. The frequency from Wednesday the 30. march 2016 16:00 to Thursday the 31. march 2016 07:00.

\section{B. Simulated Unidirectional FNR Provision}

The most important factor when calculating the revenue of unidirectional FNR is the number of whole hours the service can be performed before the battery is full. The time the $\mathrm{EV}$ can perform the service is calculated as the time it takes before the energy accumulated during charging according to the control signal reaches $5.2 \mathrm{kWh}$. The time depends itself on the current which depends on the frequency. In order to calculate the range of time the service could be provided, the best and worst case scenario are defined as periods with a constant frequency of $49.9 \mathrm{~Hz}$ and $50.1 \mathrm{~Hz}$, respectively. This is seen in table II.
Though state of the art AC/DC converters can have an efficiency over $\eta=99 \%$ mass produced EVs with a single phase charger have an efficiency of $\eta=70-90 \%$ [14]. While the low efficiency has a negative effect on the energy consumption it has a positive effect on the time the service can be provided as it takes longer before the battery is fully charged. A conservative estimate from the perspective of grid services is an efficiency of $\eta=90 \%$, which is used for the calculations. This bid is very conservative as the efficiency generally is lower when charging with lower power which is the case when delivering FNR.

TABLE II

THE TIME UNIDIRECTIONAL FNR CAN BE PROVIDED

\begin{tabular}{|l|c|c|c|c|}
\hline Case & Mean & Mean & Time & Time \\
\hline & Frequency & Current & $\eta=100 \%$ & $\eta=90 \%$ \\
\hline Best & $49.9 \mathrm{~Hz}$ & $6 \mathrm{~A}$ & $3.8 \mathrm{~h}$ & $4.2 \mathrm{~h}$ \\
\hline Mean & $50.0 \mathrm{~Hz}$ & $11 \mathrm{~A}$ & $2.1 \mathrm{~h}$ & $2.3 \mathrm{~h}$ \\
\hline Worst & $50.1 \mathrm{~Hz}$ & $16 \mathrm{~A}$ & $1.4 \mathrm{~h}$ & $1.6 \mathrm{~h}$ \\
\hline
\end{tabular}

From table II, it is estimated that the yearly mean time the service can be performed is approximately 2 hours a day. Using an intelligent prediction method based on historical frequency data to choose the time to deliver the service it could be possible to achieve a mean closer to the best case. This is therefore also used for the calculations. With the specified driving distance it is very unlikely that the $\mathrm{EV}$ will be available with less than 2 hours so the worst case is considered unlikely.

The charging current is as an example calculated when the service is provided from midnight on the previously specified day. Midnight is chosen because it would be the best time to perform the service as the compensation is much higher and the frequency generally is lower.

Taking into account a loss of $10 \%$ in the charger the accumulated energy in the battery is calculated and the charge is stopped when it reaches $5.2 \mathrm{kWh}$. This is seen in Fig. 6 . It is seen that the EV is able to perform the service for 4

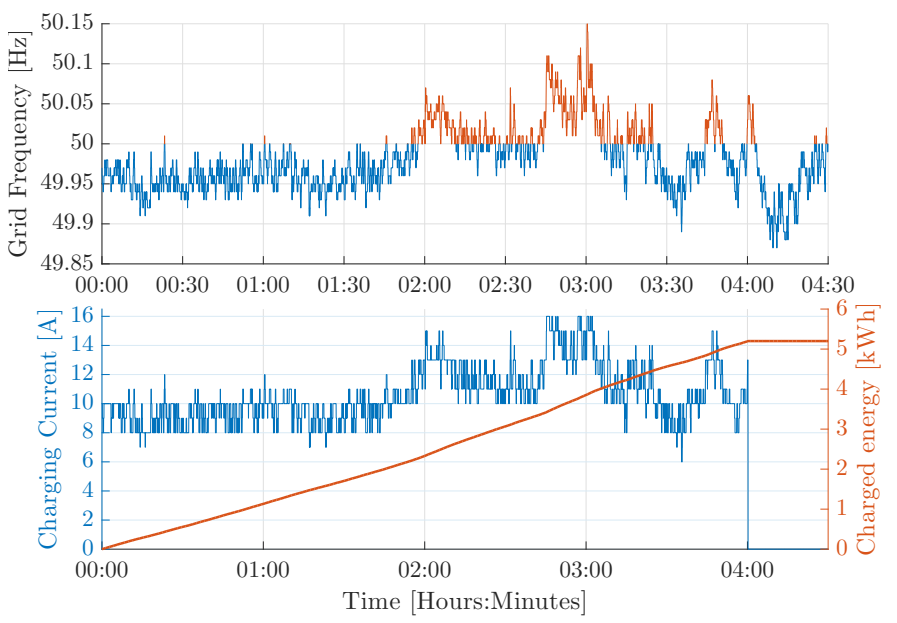

Fig. 6. Charging current and accumulated energy on a typical day. Mean of Frequency $=49.98 \mathrm{~Hz}$. 
hours in the specific case with the measured frequency. This length is closer to the best case than to the mean case even though mean frequency is closer to the mean of $50 \mathrm{~Hz}$. This is because the EV only can be set to charge with an integer current so when $11.9 \mathrm{~A}$ is needed it is asked to charge with 11 A.

For the best and mean cases the yearly earnings are calculated based on the prices seen in Fig. 1. This is found in table III.

TABLE III

ESTIMATE OF YEARLY REVENUE PERFORMING UNIDIRECTIONAL FNR.

\begin{tabular}{|l|l|l|c|c|}
\hline Case & $\begin{array}{l}\text { Providing } \\
\text { time }\end{array}$ & $\begin{array}{l}\text { Hourly } \\
\text { capacity }\end{array}$ & $\begin{array}{c}\text { Daily } \\
\text { capacity }\end{array}$ & $\begin{array}{c}\text { Yearly } \\
\text { payment }\end{array}$ \\
\hline Mean & 2 hours & $1.15 \mathrm{~kW}$ & $2.3 \mathrm{kWh}$ & 27.9 EUR \\
\hline Best & 4 hours & $1.15 \mathrm{~kW}$ & $4.6 \mathrm{kWh}$ & $56.1 \mathrm{EUR}$ \\
\hline
\end{tabular}

\section{Simulated V2G FNR provision}

As V2G theoretically can be provided indefinitely is it more a question of avoiding saturation when the battery temporarily is fully charged or discharged

If the loss in the charger is the same in both directions means that when the EV is charging with $1 \mathrm{~kW}$ the battery only receives $0.9 \mathrm{~kW}$ and when the $\mathrm{EV}$ is asked to discharge with $1 \mathrm{~kW}$ the battery has has to deliver $1.1 \mathrm{~kW}$. This difference causes a falling SOC even though the mean frequency is 50 $\mathrm{Hz}$. The owner needs the EV to have received a positive amount of energy at 07:00 in the morning. A way of avoiding this problem is to set the charging reference higher i.e. 3 A with a charging range of $\pm 13 \mathrm{~A}$ but that results in a reduction of the available power and thereby in a reduction in the revenues. An alternative solution to that problem would be to only perform the service until 04:00 and then charge with full power for the rest of the period. The first method is chosen as it gives the possibility to adjust the bias during the charge and thereby maximise the revenue no matter how long the EV is parked. The accumulated energy can be seen in Fig. 7. A bias of $3 \mathrm{~A}$ is chosen as it makes sure that the EV charges an acceptable amount of energy during the night. A higher bias might be needed if the loss is too high.

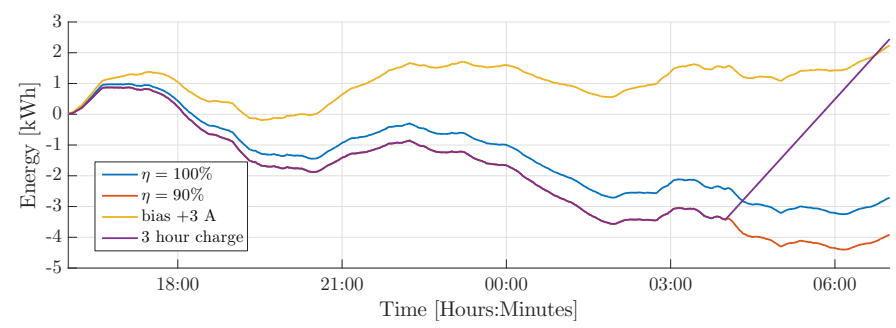

Fig. 7. Accumulated energy when performing V2G from 16:00.

The yearly earnings for the case with no correction and the two correction methods are seen in table IV. The same kind of frequency based cases that were made for the unidirectional case are not made for $\mathrm{V} 2 \mathrm{G}$ because it is not time limited in the same way that unidirectional charging is.

TABLE IV

ESTIMATE OF YEARLY REVENUE PERFORMING V2G FNR WITH $\eta=90 \%$.

\begin{tabular}{|l|l|l|c|c|}
\hline Method & $\begin{array}{l}\text { Providing } \\
\text { time }\end{array}$ & $\begin{array}{l}\text { Hourly } \\
\text { capacity }\end{array}$ & $\begin{array}{c}\text { Daily } \\
\text { capacity }\end{array}$ & $\begin{array}{c}\text { Yearly } \\
\text { payment }\end{array}$ \\
\hline No bias & 15 hours & $3.7 \mathrm{~kW}$ & $55.2 \mathrm{kWh}$ & 458.1 EUR \\
\hline Bias +3 A & 15 hours & $3.0 \mathrm{~kW}$ & $44.9 \mathrm{kWh}$ & 371.4 EUR \\
\hline 3 hour charge & 12 hours & $3.7 \mathrm{~kW}$ & $44.2 \mathrm{kWh}$ & 378.3 EUR \\
\hline
\end{tabular}

\section{Revenue Comparison}

The yearly revenue for both methods is calculated as if the service is being performed every day for a year. The most realistic cases are compared in table $\mathrm{V}$.

TABLE V

REVENUE COMPARISON.

\begin{tabular}{|l|l|l|c|}
\hline Method & $\begin{array}{l}\text { Providing } \\
\text { time }\end{array}$ & $\begin{array}{l}\text { Hourly } \\
\text { capacity }\end{array}$ & $\begin{array}{c}\text { Yearly } \\
\text { payment }\end{array}$ \\
\hline UNI Best case & 4 hours & $1.2 \mathrm{~kW}$ & 56.2 EUR \\
\hline UNI Mean case & 2 hours & $1.2 \mathrm{~kW}$ & 27.9 EUR \\
\hline V2G & 15 hours & $3 \mathrm{~kW}$ & 371.5 EUR \\
\hline
\end{tabular}

This comparison means that the range of the ratio when performing unidirectional FNR and V2G FNR is:

$$
\text { ratio }_{\text {Best }}=\frac{371.5}{56.2}=6.6 \quad \text { ratio }_{\text {Mean }}=\frac{371.5}{27.9}=13.3
$$

The time the EV can perform unidirectional FNR is the most sensitive parameter to the resulting end ratio. It is however very certain that it is between 2 and 4 hours in the case with a daily consumption of $5.2 k W h$. The earnings performing V2G are mainly sensitive to changes in the assumptions regarding the efficiency of the charger that corresponds to the necessary size of the bias.

If the EV just starts performing Unidirectional FNR at midnight it would only be possible to guaranteed 2 hours of service but there is potential delivering the service up to 4 hours which is the best case scenario. Therefore is it very likely that the actual ratio is in range 6.6-13.3 and closest 13.3 if the service is performed today.

\section{EXPERIMENTAL VALIDATION}

\section{A. Unidirectional Experiment}

The Citroën Berlingo Electri under test is, as most EVs on the market, charged via an Electric Vehicle Supply Equipment (EVSE) that by a PWM signal informs the EV how much power it is allowed to charge. The EV then sets the charging level close to this maximum limit. An Ethernet controlled EVSE can then be used by the aggregator to control the Berlingo Electric as a variable load.

In Fig. 8 is it seen how the EV follows the control signal from the aggregator with a very high precision and a delay below 1 second, which is the sampling rate of the 
frequency. The EV lives up to the grid code regarding FNR by implementing the specified droop curve on the saved frequency measurement. The EV only reaches a current of $15.3 \mathrm{~A}$ when it is set to charge with $16 \mathrm{~A}$. It is however only for short durations where the longest is 40 seconds. Apart from $16 \mathrm{~A}$, the EV follows the control signal very accurately over the whole range of charging currents.

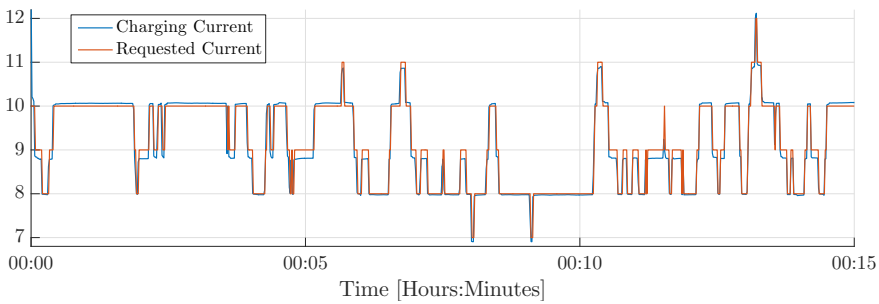

Fig. 8. First 15 minutes of Citroen Berlingo performing unidirectional FNR on the stored frequency.

When the SOC is above $90 \%$ the Battery Management System (BMS) will switch from Constant Current to Constant Voltage charging mode, therefore the current will be progressively be reduced until the SOC is $100 \%$. It is seen in Fig. 9 that in the case of the Berlingo Electric the EV the BMS takes over the control of the charging process 45 minutes before the SOC reaches $100 \%$. That means 45 minutes less to provide FNR. One way to mitigate this issue would be to set the maximum SOC to $80 \%$ and stop providing grid services from this point (this could be done by the aggregator, or by the user who could set a limitation directly in the vehicle). Nissan LEAF has a setting for this in order to minimise the degradation of the battery. If $80 \%$ of the battery is enough to the daily usage it is possible to never enter the levelling area and perform FNR during the entire charge.

The Berlingo Electric is discharged to a SOC of $60 \%$ before it is connected to the EVSE running the FNR algorithm on the frequency measurement from midnight on March 30 and the next 7 hours. Unfortunately, the publicly displayed SOC information is not as accurate as we would like it to be for research experiments. The EV is discharged until the bar inside the EV shows approximately the wanted level. Therefore the experiment can not be used to verify the time the EV can perform the service with $5.2 \mathrm{kWh}$ but rather how well it does it.

The top graph on Fig. 9 shows the frequency at the specific time and the bottom graph shows the current charged by the $\mathrm{EV}$, measured at the grid side. The bottom graph shows the charged energy which is the accumulation of the measured active power multiplied with the chosen efficiency of $\eta=$ $90 \%$. The EVs specified capacity is $22.5 \mathrm{kWh}$. When it is discharged approximately $40 \%$, it has an available capacity of $9 \mathrm{kWh}$. The chosen efficiency appears to be a close estimate as the curve of the accumulated energy with loss almost reaches 9 $\mathrm{kWh}$. It is difficult to determine the time the Berlingo Electric can perform the service but if it is assumed that the loss of $10 \%$ is accurate does the figure show that it can perform the service in 4 hours before it has charged $5.2 \mathrm{kWh}$. That is the same as the simulated results.

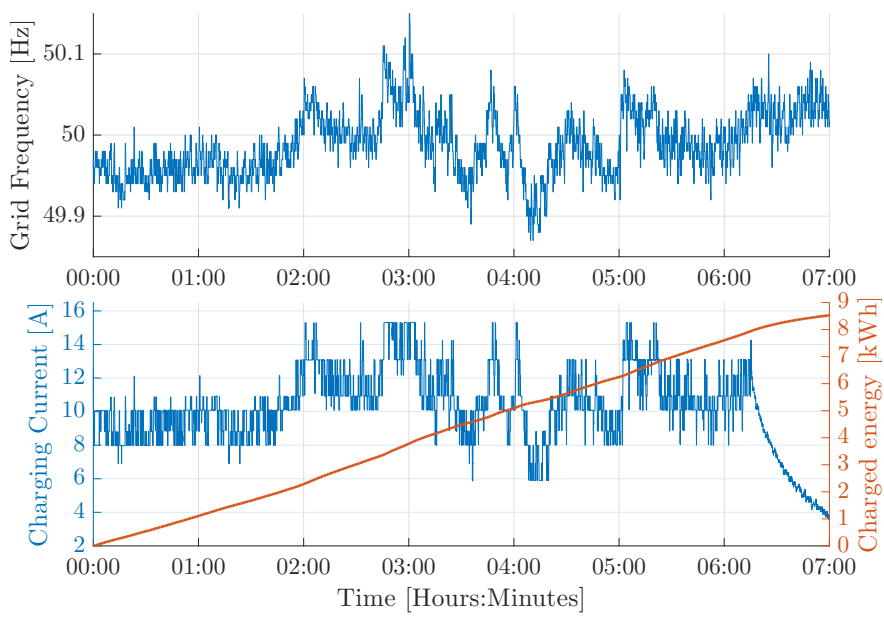

Fig. 9. Citroen Berlingo performing unidirectional FNR on the stored frequency for 7 hours.

\section{B. V2G experiment}

The Endesa Novare Vehicle to Microgrid project has developed a remote controlled $10 \mathrm{~kW}$ bidirectional charger that utilises the CHAdeMO standard [15]. One of these chargers are used to perform the experiment with a Nissan LEAF via the CHAdeMo plug.

The aggregator is set to perform FNR with a $3 \mathrm{~kW}$ and a bias of $0.7 \mathrm{~kW}$. Fig. 10 shows 10 minutes of the experiment. On the left axis is seen the bias, the measured consumption and the request from the aggregator which corresponds to the frequency seen on the right axis. The power is seen from the EV perspective where a positive amount means that the EV is charging. It is noted that when the frequency is close to $50 \mathrm{~Hz}$ is the power close to the bias. There is approximately 5 seconds of delay, which means that the EV does not react accurately to spikes that last less than than that.

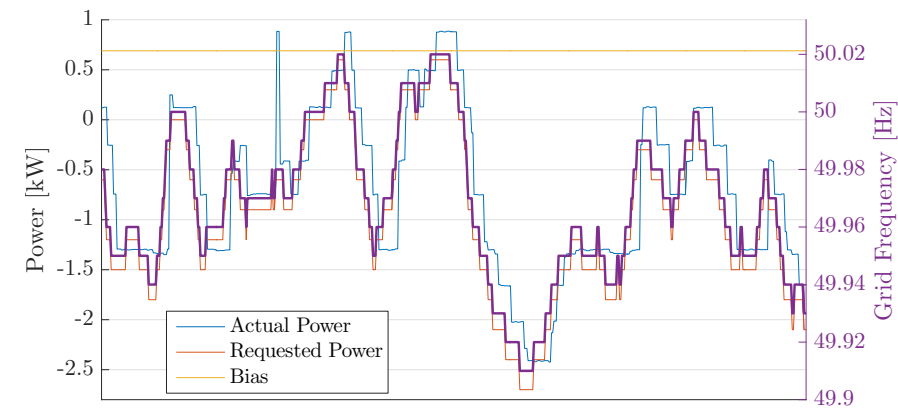

Fig. 10. Frequency, Request, Response and bias for 10 minutes

Fig. 11 shows the requested and actual charging power for 15 hours. The test was started when the SOC was approximately $78 \%$ which corresponds to the Nissa LEAF having an available capacity of $5.2 \mathrm{kWh}$. Even though the SOC is not 
logged it can be concluded that the EV did not reach saturation and is able to perform the experiment for 15 continuous hours.

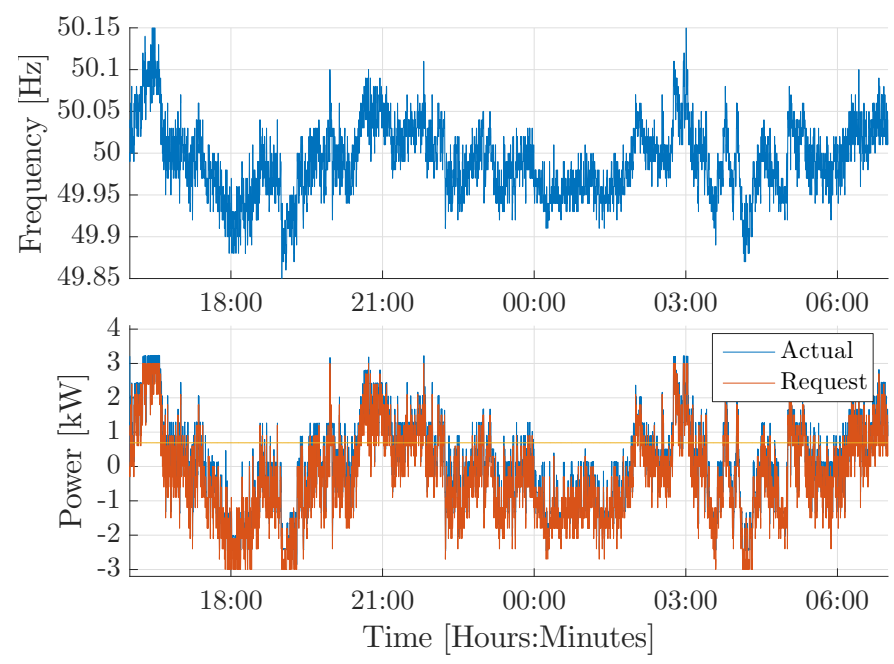

Fig. 11. Request, Response and bias for the whole 15 hour period.

\section{DISCUSSION AND CONCLUSION}

It is shown that the EVs are able to perform unidirectional FNR with a small delay of down to $1 \mathrm{~s}$ and $\mathrm{V} 2 \mathrm{G}$ down to 5 $s$ even though FNR only requires an activation time of less than $150 \mathrm{~s}$. The experiments show that the EVs are able to deliver the power quickly and accurate when only aggregating one EV at the time. More complex problems will occur when trying to aggregate a fleet of EVs, as the aggregator needs the guarantee that the bid can be delivered even though not all EVs are available at all times. Aggregating a fleet gives the advantage that not all EVs need to charge with the same current so they only charge at the rate where the efficiency is the highest.

A range of the ratio $6.6 \div 13.3 \mathrm{~V} 2 \mathrm{G}$ is more lucrative than unidirectional FNR is found. The ratio is a result of the specific case with the chosen daily driving distance. It is based on a comparison where both vehicles have a power converter of 16 A because that is what is in most unidirectional EVs. V2G are however not limited by this as the external charger can be made for much higher powers. Using the new $10 \mathrm{~kW}$ Endesa chargers there is possibility of earnings 3 times more than the ones presented for $\mathrm{V} 2 \mathrm{G}$ offering $3 \mathrm{~kW}$, assuming that the aggregator controls the SOC by setting the bias.

The earnings performing unidirectional FNR is so low that it is not viable if the consumers have any cost of hardware or discomfort performing the service. The yearly payment of 56.1 EUR is the highest possible payment the EV owner could expect to receive unless the daily driving distance is higher. Because of this is $\mathrm{V} 2 \mathrm{G}$ a much more viable solution as it can be performed longer and with higher power independent of the driven kilometres.

As the OEM is one of the biggest stakeholders in creating added value to the EV owners as a way to make progress in the $\mathrm{EV}$ market development it could benefit them to make EVs with internal bidirectional chargers for easier access to performing grid services. Further work could include and analysis of the business model for the OEM including development, pruction and operating cost.

The found earnings describe the raw market value of the service provided by one EV and not what the individual EV owner will receive as there will be costs of combined with being a part of an aggregated fleet.

\section{ACKNOWLEDGEMENTS}

This work is supported by the Danish Research Project "NIKOLA - Intelligent Electric Vehicle Integration"- under ForskEL kontrakt nr. 2013-1-12088.

\section{REFERENCES}

[1] Kristien Clement-Nyns, Edwin Haesen and Johan Driesen, "The Impact of Charging Plug-In Hybrid Electric Vehicles on a Residential Distribution Grid":IEEE TRANSACTIONS ON POWER SYSTEMS, VOL. 25, NO. 1, FEBRUARY 2010

[2] Baha M. Al-Alawi and Thomas H. Bradley. "Review of hybrid, plugin hybrid, and electric vehicle market modeling studies. Renewable and Sustainable Energy Reviews", 21(0):190 - 203, 2013.

[3] Willett Kempton and Jasna Tomic', "Vehicle-to-grid power fundamentals: Calculating capacity and net revenue", Journal of Power Sources 144 (2005) 268-279

[4] J. A. Pecas Lopes, F. J. Soares and P. M. Rocha Almeida, Identifying Management Procedures to Deal with Connection of Electric Vehicles in the Grid

[5] Willett Kempton and Jasna Tomic', "Vehicle-to-grid power implementation: From stabilizing the grid to supporting large-scale renewable energy.” Journal of Power Sources, 144(1):280-294, 2005.

[6] P.B. Andersen, M. Marinelli, O. J. Olesen, C.A.Andersen, G. Poilasne, B. Christensen, O. Alm, "The Nikola project - intelligent electric vehicle integration”, in Proc. IEEE ISGT Europe, 2014.

[7] Paul Codani and Marc Petit, "Participation of an electric vehicle fleet to primary frequency control in France": Int. J. Electric and Hybrid Vehicles, Vol. 7, No. 3, 2015

[8] Energinet.dk, Ancillary services to be delivered in Denmark - Tender conditions. Available: https://www.energinet.dk/EN/El/Systemydelser-for-el/ Sider/Systemydelserforel.aspx

[9] Hjalmar Christiansen and Britt Zoga Skougaard Documentation of the Danish National Travel Servey: DTU Transport, June 2015

[10] The Datasheet of Citroen Berlingo Electric. Available: http://www.citroen.dk/Resources/Content/DK/07_PDF/Tech_specs/ techspec_BerlingoElectric.pdf

[11] M. Marinelli, S. Martinenas, K. Knezovic, and P. B. Andersen, ”Validating a centralized approach to primary frequency control with seriesproduced electric vehicles,” J. of Energy Storage, vol. 7, pp.63-73, Aug. 2016.

[12] K. Knezović, M. Marinelli, P. Codani, and Y. Perez, "Distribution Grid Services and Flexibility Provision by Electric Vehicles: a Review of Options," Universities Power Engineering Conference (UPEC), 2015 Proceedings of the 50th International, pp. 1-6, Staffordshire, 1-4 Sep. 2015.

[13] S. Martinenas, M. Marinelli, P. B. Andersen, and C. Træholt, "Implementation and Demonstration of Grid Frequency Support by V2G Enabled Electric Vehicle," Universities Power Engineering Conference (UPEC), 2014 Proceedings of the 49th International, pp.1-6, Cluj Napoca, 2-5 Sep. 2014.

[14] Andreas Kieldsen, Andreas Thingvad, Sergejus Martinenas and Thomas Meier Srensen, Efficiency Test Method for Electric Vehicle Chargers, EVS29 Symposium, Montreal, Quebec, Canada, June 19-22, 2016

[15] Press release from Endesa describing the $10 \mathrm{~kW}$ bidirectional EV chargers. Evailable: http://www.endesa.com/en/saladeprensa/noticias/ new-bidirectional-charging-point 